\title{
Application of allergic rhinitis and its impact on asthma guidelines in terms of classification, risk factors, quality of life and co-morbidities in allergic rhinitis patients in Northern India
}

\author{
Anmol Kumar Agarwal, Rohit Sharma*, Vinit Sharma
}

Department of ENT and Head and Neck Surgery, SRMS IMS, Bareilly, Uttar Pradesh, India

\author{
Received: 17 February 2020 \\ Revised: 02 April 2020 \\ Accepted: 28 April 2020 \\ *Correspondence: \\ Dr. Rohit Sharma, \\ E-mail: rohitsharma.dr@gmail.com
}

Copyright: () the author(s), publisher and licensee Medip Academy. This is an open-access article distributed under the terms of the Creative Commons Attribution Non-Commercial License, which permits unrestricted non-commercial use, distribution, and reproduction in any medium, provided the original work is properly cited.

\begin{abstract}
Background: Despite the high prevalence of allergic rhinitis, there are only few studies on application of ARIA (allergic rhinitis and its impact on asthma) guidelines.

Methods: It was a prospective study of 164 patients. Based on ARIA guidelines; patients were graded for severity, risk factors studied, co morbidities documented and quality of life assessed using rhinoconjunctivitis quality of life questionnaire (RQLQ).

Results: A total of 164 cases were studied between the age group 10-72 years of which 56.1\% were males. Most common trigger observed was dust $(56.1 \%)$. Allergic conjunctivitis was most common co-morbidity associated. Using RQLQ it was observed that ARIA.

Conclusions: ARIA guidelines appropriately classify allergic rhinitis, determines risk factors and associated comorbidities. RQLQ can be used to determine quality of life in allergic rhinitis.
\end{abstract}

Keywords: ARIA, RQLQ, Comorbidities, Classification, Quality of life, Risk factors

\section{INTRODUCTION}

Allergic rhinitis (AR) is clinically defined as a symptomatic disorder of the nose induced after allergen exposure by an IgE-mediated inflammation. Symptoms of AR include rhinorrhea, nasal obstruction, nasal itching and sneezing which are reversible spontaneously or with treatment.

It is a global health problem that causes major illness and disability worldwide. Patients from all countries, all ethnic groups and all ages suffer from AR. AR affects social life, sleep, school and work. The economic impact of $\mathrm{AR}$ is often underestimated because the disease does not induce elevated direct costs. However, the indirect costs are substantial. ${ }^{1}$ Both AR and asthma are systemic inflammatory conditions and often are co-morbidities.

Impact is correlated with the severity of symptoms. AR is frequently associated with several co morbidities, including asthma, and physicians are encouraged to ask AR patients about symptoms of asthma.,

AR was conventionally classified into seasonal allergic rhinitis (SAR) and perennial allergic rhinitis (PAR) based on time of exposure. The conventional classification has some limitations from a therapeutic standpoint due to its poor association with clinical symptoms. ${ }^{4}$ 
The allergic rhinitis and its impact on asthma (ARIA) workshop was held at the World Health Organization in 1999 and certain guidelines for AR were laid.

Despite the high prevalence of AR and its co morbidities, there are only few studies on application of ARIA guidelines. Hence this study was undertaken to elucidate the ARIA guidelines in terms of classification, risk factors, severity, quality of life and co morbidities in AR patients in Northern India.

\section{METHODS}

The study was a prospective study in which total 164 cases were taken. It was conducted in the Department of ENT and Head and Neck Surgery at SRMS IMS in patients presenting in ENT OPD and clinically diagnosed as AR, after the approval by the Research or Ethics Committee during November 2016 to July 2019. The patients included in this study were those who presented with signs and symptoms of AR which were watery rhinorrhea, nasal obstruction, nasal pruritis, sneezing especially paroxysmal and impaired quality of life, sleep, school and work.

Those excluded from the study had symptoms that are usually not associated with AR which are unilateral symptoms, mucopurulent rhinorrhea, post nasal drip, pain, recurrent epistaxis, anosmia. Also, the conditions which mimic AR e.g. infectious rhinitis (rhino sinusitis), work related rhinitis, drug induced rhinitis, atrophic rhinitis, food induced rhinitis were excluded from the study. Moreover, Endoscopic findings suggestive of polyps and/or mucopurulent discharge from middle meatus and CT changes suggestive of mucosal changes within ostiomeatal complex and/or sinuses were also excluded from the study.

A detailed history of AR and other symptoms like eye congestion, recurrent or episodic headache, and symptoms associated with social life, work and school was taken. Besides this, a complete ENT examination and haematological investigations were also carried out. The comorbidities assessed were documented on the basis of clinical presentation and were conjunctivitis, rhinosinusitis, nasal polyposis, adenoid hypertrophy, tubal dysfunction, otitis media with effusion (OME), chronic cough, laryngitis and gastro esophageal reflux disorder (GERD).

Quality of life and health status for the patients of AR was determined by rhino conjunctivitis quality of life questionnaire (RQLQ) self-administered Hindi version developed by Elizabeth Jupiner, MCSP, MSc and translated by MAPI Research Institute with Local Coordination of Dr. Abha Saxena and printed by QOL Technologies Ltd in 2002.

Statistical testing was conducted with the statistical package for the social science system version SPSS
17.0. Continuous variables are presented as mean $\pm \mathrm{SD}$, and categorical variables are presented as absolute numbers and percentage. Nominal categorical data between the groups were compared using Chi-squared test or Fisher's exact test as appropriate. $\mathrm{P}<0.05$ was considered statistically significant while $\mathrm{p}<0.001$ was considered statistically highly significant.

\section{RESULTS}

A total of 164 cases were studied between the age group of 10 years to 72 years and the mean age was 30.24 years. Maximum patients were of age group 21-30 years contributing $40.2 \%$ followed by $31-40$ years contributing $22.6 \%$ as depicted in Table 1 .

Table 1: Age distribution and classification in patients of $\mathbf{A R}$.

\begin{tabular}{|lll|}
\hline Variables & Frequency & $\%$ \\
\hline Age groups (in years) & & \\
\hline $10-20$ & 36 & 22.0 \\
\hline $21-30$ & 66 & 40.2 \\
\hline $31-40$ & 37 & 22.6 \\
\hline $41-50$ & 14 & 8.5 \\
\hline$>50$ & 11 & 6.7 \\
\hline Total & 164 & 100 \\
\hline Mean \pm SD & $30.24 \pm 11.92$ & \\
\hline Median & 27.5 & \\
\hline Min-Max & $10-72$ & \\
\hline Classification of AR & & 56.1 \\
\hline Mild intermittent & 92 & 29.9 \\
\hline Mild persistent & 49 & 3.0 \\
\hline $\begin{array}{l}\text { Moderate to severe } \\
\text { intermittent }\end{array}$ & 5 & 11.0 \\
\hline $\begin{array}{l}\text { Moderate to severe } \\
\text { persistent }\end{array}$ & 18 & 100 \\
\hline Total & 164 & \\
\hline
\end{tabular}

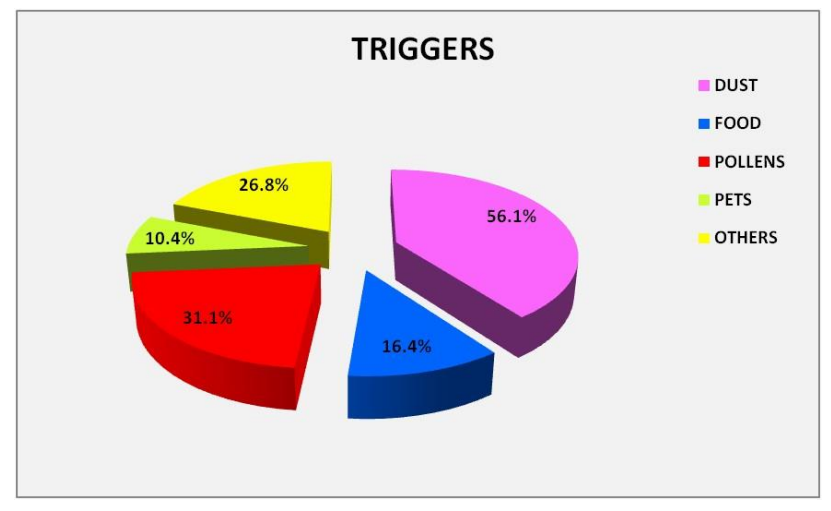

Figure 1: Triggers of AR.

In the past AR was classified as 'seasonal' and 'perennial'. Based on ARIA guidelines it is now classified as intermittent or persistent and mild or moderate to severe. In our study it is illustrated that most 
of the patients had mild intermittent AR (56.1\%) and the least number of patients had moderate to severe intermittent AR (3\%) (Table 1).

It was found that out of 164 cases, 72 (43.9\%) were females and $92(56.1 \%)$ were males and most of the patients were of mild intermittent AR in both males and females.

$\mathrm{AR}$ is attributed to many risk factors and triggers which are implicated in its aetiopathogenesis and can be outdoor and indoor allergens. In the present study dust, food, pollens, pets, others (other than the allergens mentioned in this study) were studied upon and it was observed that in $56.1 \%$ cases dust was the triggering factor followed by pollens $(31.1 \%)$ (Figure 1). More or less all the studied triggers were most commonly seen in patients of mild intermittent type and least in moderate to severe intermittent type as illustrated in Figure 2.

AR is usually associated with co-morbidities as a result of 'unified airway disease' affecting the entire respiratory pathway. Co-morbidities can be classified as due to a common causal pathway (e.g. allergy) or as a complicating co-morbidity (complication of infections due to mucosa swelling, stasis of mucous). In the present study allergic conjunctivitis was the most common comorbidity associated (48.8\%) while nasal polyposis and Rhinosinusitis was not observed in any patient as illustrated in Table 2.

It has been observed that in the present study except tubal dysfunction, OME and laryngitis rest of the comorbidities were most commonly seen in mild intermittent $\mathrm{AR}$ and it was statistically significant as illustrated in Table 2.

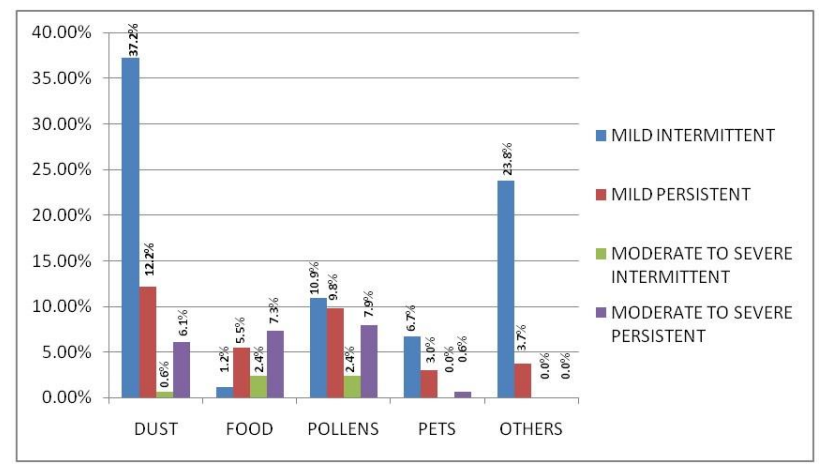

Figure 2: Association of triggers with classification of AR.

Table 2: Co-morbidities and their association with classification of $A R(n=164)$.

\begin{tabular}{|lllllll|}
\hline Comorbidities & Total & $\begin{array}{l}\text { Mild } \\
\text { intermittent }\end{array}$ & $\begin{array}{l}\text { Mild } \\
\text { persistent }\end{array}$ & $\begin{array}{l}\text { Moderate to } \\
\text { severe } \\
\text { intermittent }\end{array}$ & $\begin{array}{l}\text { Moderate to } \\
\text { severe } \\
\text { persistent }\end{array}$ \\
\cline { 2 - 4 } & $\mathbf{N}(\boldsymbol{\%})$ & $\mathbf{N}(\boldsymbol{\%})$ & $\mathbf{N}(\%)$ & $\mathbf{N}(\%)$ & N (\%) & Palue \\
\hline $\begin{array}{l}\text { Allergic } \\
\text { conjunctivitis }\end{array}$ & $80(48.8)$ & $37(22.6)$ & $26(15.9)$ & $3(1.8)$ & $14(8.5)$ & 0.025 \\
\hline Rhinosinusitis & $0(0.0)$ & $0(0.0)$ & $0(0.0)$ & $0(0.0)$ & $0(0.0)$ & - \\
\hline Nasal polyposis & $0(0.0)$ & $0(0.0)$ & $0(0.0)$ & $0(0.0)$ & $0(0.0)$ & - \\
\hline $\begin{array}{l}\text { Adenoid } \\
\text { hypertrophy }\end{array}$ & $8(4.9)$ & $8(4.9)$ & $0(0.0)$ & $0(0.0)$ & $0(0.0)$ & 0.086 \\
\hline Tubal dysfunction & $44(26.8)$ & $14(8.5)$ & $22(13.4)$ & $1(0.6)$ & $7(4.3)$ & 0.001 \\
\hline $\begin{array}{l}\text { Otitis media with } \\
\text { effusion }\end{array}$ & $27(16.5)$ & $3(1.8)$ & $19(11.6)$ & $1(0.6)$ & $4(2.4)$ & $<0.001$ \\
\hline Chronic cough & $14(8.5)$ & $5(3.0)$ & $2(1.2)$ & $2(1.2)$ & $5(3.0)$ & 0.001 \\
\hline Laryngitis & $14(8.5)$ & $5(3.0)$ & $1(0.6)$ & $1(0.6)$ & $7(4.3)$ & 0.001 \\
\hline GERD & $32(19.5)$ & $13(7.9)$ & $13(7.9)$ & $0(0.0)$ & $6(3.7)$ & 0.084 \\
\hline
\end{tabular}

Table 3: Three most important activities in which patient have been limited by his/her nose/eye symptoms during the last week RQLQ.

\begin{tabular}{|llll|}
\hline \multirow{2}{*}{ Activities } & Activity $\mathbf{~ A c t i v i t y ~}$ & Activity $\mathbf{3}$ \\
\hline Bicycling & $\mathbf{N}(\mathbf{\%})$ & $\mathbf{N}(\mathbf{\%})$ & $\mathbf{N}(\mathbf{\%})$ \\
\hline Reading & $11(6.7)$ & $8(4.9)$ & $2(1.2)$ \\
\hline Shopping & $6(3.7)$ & $5(3.0)$ & $8(4.9)$ \\
\hline Doing home maintenance & $7(4.3)$ & $3(1.8)$ & $4(2.4)$ \\
\hline Doing your housework & $11(6.7)$ & $14(8.5)$ & $6(3.7)$ \\
\hline Gardening & $7(4.3)$ & $9(5.5)$ & $11(6.7)$ \\
\hline Watching tv & $17(10.4)$ & $11(6.7)$ & $8(4.9)$ \\
\hline
\end{tabular}




\begin{tabular}{|llll|}
\hline \multirow{2}{*}{ Activities } & Activity & Activity & Activity 3 \\
\hline Exercising or working out & $\mathbf{N}(\boldsymbol{\%})$ & $\mathbf{N}(\boldsymbol{\%})$ & $\mathbf{N}(\mathbf{\%})$ \\
\hline Hot/cold eatables & $0(0.0)$ & $3(1.8)$ & $2(1.2)$ \\
\hline Using a computer & $9(5.5)$ & $6(3.7)$ & $7(4.3)$ \\
\hline Cleaning the lawn & $3(1.8)$ & $5(3.0)$ & $8(4.9)$ \\
\hline Playing with pets & $6(3.7)$ & $7(4.3)$ & $11(6.7)$ \\
\hline Eating spicy foods & $10(6.1)$ & $7(4.3)$ & $7(4.3)$ \\
\hline Playing sports & $2(1.2)$ & $5(3.0)$ & $7(4.3)$ \\
\hline Driving & $3(1.8)$ & $6(3.7)$ & $4(2.4)$ \\
\hline Making chapatis & $7(4.3)$ & $8(4.9)$ & $3(1.8)$ \\
\hline Doing regular social activities & $5(3.0)$ & $9(5.5)$ & $8(4.9)$ \\
\hline Having sexual relations & $1(0.6)$ & $0(0.0)$ & $3(1.8)$ \\
\hline Visiting temple & $0(0.0)$ & $0(0.0)$ & $0(0.0)$ \\
\hline Talking & $2(1.2)$ & $3(1.8)$ & $4(2.4)$ \\
\hline Eating & $3(1.8)$ & $1(0.6)$ & $1(0.6)$ \\
\hline Vacuuming & $2(1.2)$ & $5(3.0)$ & $7(4.3)$ \\
\hline Visiting friends or relatives & $5(3.0)$ & $3(1.8)$ & $8(4.9)$ \\
\hline Going for a walk & $0(0.0)$ & $2(1.2)$ & $5(3.0)$ \\
\hline Worshipping god & $4(2.4)$ & $3(1.8)$ & $6(3.7)$ \\
\hline Stuck in traffic & $1(0.6)$ & $0(0.0)$ & $2(1.2)$ \\
\hline Carrying out your activities at work & $3(1.8)$ & $2(1.2)$ & $4(2.4)$ \\
\hline Sitting outdoors & $5(3.0)$ & $2(1.2)$ & $6(3.7)$ \\
\hline Taking children to the park & $3(1.8)$ & $4(2.4)$ & $2(1.2)$ \\
\hline Bathing & $0(0.0)$ & $3(1.8)$ & $2(1.2)$ \\
\hline Cooking food over stove & $0(0.0)$ & $2(1.2)$ & $1(0.6)$ \\
\hline Using public transport & $5(3.0)$ & $11(6.7)$ & $4(2.4)$ \\
\hline Setting bedsheet & $3(1.8)$ & $5(3.0)$ & $1(0.6)$ \\
\hline Cooking vegetables & $0(0.0)$ & $0(0.0)$ & $0(0.0)$ \\
\hline Handling wheat & $11(6.7)$ & $5(3.0)$ & $6(3.7)$ \\
\hline & $7(4.3)$ & $4(2.4)$ & $2(1.2)$ \\
\hline
\end{tabular}

Table 4: RQLQ association of activity 1 with classification of AR.

\begin{tabular}{|lllllll|}
\hline Activity 1 & Score & $\begin{array}{l}\text { Class } \\
\text { Mild } \\
\text { intermittent }\end{array}$ & $\begin{array}{l}\text { Mild } \\
\text { persistent }\end{array}$ & $\begin{array}{l}\text { Moderate to } \\
\text { severe intermittent }\end{array}$ & $\begin{array}{l}\text { Moderate to } \\
\text { severe persistent }\end{array}$ & P value \\
\hline Not troubled & 0 & $0(0.0)$ & $0(0.0)$ & $0(0.0)$ & $0(0.0)$ & - \\
\hline $\begin{array}{l}\text { Hardly troubled at } \\
\text { all }\end{array}$ & 1 & $13(7.9)$ & $3(1.8)$ & $0(0.0)$ & $0(0.0)$ & 0.156 \\
\hline Somewhat troubled & 2 & $59(36.0)$ & $16(9.8)$ & $2(1.2)$ & $0(0.0)$ & $<0.001$ \\
\hline $\begin{array}{l}\text { Moderately } \\
\text { troubled }\end{array}$ & 3 & $19(11.6)$ & $28(17.1)$ & $2(1.2)$ & $2(1.2)$ & $<0.001$ \\
\hline Quite a bit troubled & 4 & $1(0.6)$ & $2(1.2)$ & $1(0.6)$ & $11(6.7)$ & $<0.001$ \\
\hline Very troubled & 5 & $0(0.0)$ & $0(0.0)$ & $0(0.0)$ & $5(3.0)$ & $<0.001$ \\
\hline Extremely troubled & 6 & $0(0.0)$ & $0(0.0)$ & $0(0.0)$ & $0(0.0)$ & - \\
\hline Not done & 9 & $0(0.0)$ & $0(0.0)$ & $0(0.0)$ & $0(0.0)$ & - \\
\hline
\end{tabular}

In the present study we have utilised RQLQ to determine quality of life in patients of AR.

Table 3 shows the three most important activities in which patient had been limited by his or her nose or eye symptoms during the last week RQLQ. Out of 35 activities the most common activity 1 was 'gardening' which was chosen by $17(10.4 \%)$ patients. Most common activity 2 was 'doing home maintenance' which was chosen by $14(8.5 \%)$ patients and most common activity 3 was 'moving the lawn' and 'doing your housework' which was chosen by $11(6.7 \%)$ patients. After choosing the three activities the patient had to subjectively choose how troubled he/she was by each of the chosen activity from 0-6 (not troubled- not done). 
Table 5: RQLQ- how troubled the patient had been by each of these sleep problems during the last week as result of his/her nose/eye symptoms.

\begin{tabular}{|llllllll|}
\hline & $\begin{array}{l}\text { Not } \\
\text { troubled }\end{array}$ & $\begin{array}{l}\text { Hardly } \\
\text { troubled at all }\end{array}$ & $\begin{array}{l}\text { Somewhat } \\
\text { troubled }\end{array}$ & $\begin{array}{l}\text { Moderately } \\
\text { troubled }\end{array}$ & $\begin{array}{l}\text { Quite a bit } \\
\text { troubled }\end{array}$ & $\begin{array}{l}\text { Very } \\
\text { troubled }\end{array}$ & $\begin{array}{l}\text { Extremely } \\
\text { troubled }\end{array}$ \\
& $\mathbf{0}$ & $\mathbf{1}$ & $\mathbf{2}$ & $\mathbf{3}$ & $\mathbf{4}$ & $\mathbf{5}$ & $\mathbf{6}$ \\
\hline $\begin{array}{l}\text { Sifficulty getting } \\
\text { to sleep }\end{array}$ & $72(43.9)$ & $\mathbf{N}(\boldsymbol{\%})$ & $\mathbf{N}(\boldsymbol{\%})$ & $\mathbf{N}(\boldsymbol{\%})$ & $\mathbf{N}(\boldsymbol{\%})$ & $\mathbf{N}(\mathbf{\%})$ & $\mathbf{N}(\%)$ \\
\hline $\begin{array}{l}\text { Wake up during } \\
\text { night }\end{array}$ & $86(52.4)$ & $41(25.0)$ & $24(14.6)$ & $6(3.7)$ & $5(3.0)$ & $2(1.2)$ & $0(0.0)$ \\
\hline $\begin{array}{l}\text { Lack of good } \\
\text { night sleep }\end{array}$ & $90(54.9)$ & $40(24.4)$ & $20(12.2)$ & $8(4.9)$ & $5(3.0)$ & $1(0.6)$ & $0(0.0)$ \\
\hline
\end{tabular}

Table 6: RQLQ-association of 'difficulty getting to sleep' with classification of allergic rhinitis.

\begin{tabular}{|c|c|c|c|c|c|c|}
\hline \multirow{3}{*}{$\begin{array}{l}\text { Difficulty getting to } \\
\text { sleep }\end{array}$} & \multirow{3}{*}{ Score } & \multicolumn{4}{|l|}{ Class } & \multirow{3}{*}{$P$ value } \\
\hline & & $\begin{array}{l}\text { Mild } \\
\text { intermittent }\end{array}$ & Mild persistent & $\begin{array}{l}\text { Moderate to } \\
\text { severe } \\
\text { intermittent }\end{array}$ & $\begin{array}{l}\text { Moderate to } \\
\text { severe } \\
\text { persistent }\end{array}$ & \\
\hline & & $\mathbf{N}(\%)$ & $\mathbf{N}(\%)$ & $\mathbf{N}(\%)$ & $\mathbf{N}(\%)$ & \\
\hline Not troubled & 0 & $0(0.0)$ & $0(0.0)$ & $0(0.0)$ & $0(0.0)$ & - \\
\hline Hardly troubled at all & 1 & $60(36.6)$ & $12(7.3)$ & $1(0.6)$ & $0(0.0)$ & $<0.001$ \\
\hline Somewhat troubled & 2 & $27(16.5)$ & $29(17.7)$ & $1(0.6)$ & $0(0.0)$ & $<0.001$ \\
\hline Moderately troubled & 3 & $5(3.0)$ & $21(12.8)$ & $2(1.2)$ & $4(2.4)$ & 0.001 \\
\hline Quite a bit troubled & 4 & $0(0.0)$ & $1(0.6)$ & $1(0.6)$ & $9(5.5)$ & $<0.001$ \\
\hline Very troubled & 5 & $0(0.0)$ & $0(0.0)$ & $0(0.0)$ & $5(4.0)$ & $<0.001$ \\
\hline Extremely troubled & 6 & $0(0.0)$ & $0(0.0)$ & $0(0.0)$ & $0(0.0)$ & - \\
\hline
\end{tabular}

Table 7: RQLQ-how troubled the patient had been by these problems during the last week as result of his/her nose/eye symptoms and practical problems.

\begin{tabular}{|c|c|c|c|c|c|c|c|}
\hline & $\begin{array}{l}\text { Not } \\
\text { troubled }\end{array}$ & $\begin{array}{l}\text { Hardly } \\
\text { troubled at all }\end{array}$ & $\begin{array}{l}\text { Somewhat } \\
\text { troubled }\end{array}$ & $\begin{array}{l}\text { Moderately } \\
\text { troubled }\end{array}$ & $\begin{array}{l}\text { Quite a bit } \\
\text { troubled }\end{array}$ & $\begin{array}{l}\text { Very } \\
\text { troubled }\end{array}$ & $\begin{array}{l}\text { Extremely } \\
\text { troubled }\end{array}$ \\
\hline & $\mathbf{0}$ & 1 & 2 & 3 & 4 & 5 & 6 \\
\hline & $\mathbf{N}(\%)$ & $\mathbf{N}(\%)$ & $\mathbf{N}(\%)$ & $\mathbf{N}(\%)$ & $\mathbf{N}(\%)$ & $\mathbf{N}(\%)$ & $\mathbf{N}(\%)$ \\
\hline \multicolumn{8}{|c|}{ Non-nose/eye symptoms } \\
\hline Fatigue & $27(16.5)$ & $40(24.4)$ & $60(36.6)$ & $23(14.0)$ & $13(7.9)$ & $1(0.6)$ & $0(0.0)$ \\
\hline Thirst & $29(17.7)$ & $43(26.2)$ & $40(24.4)$ & $38(23.2)$ & $10(6.1)$ & $4(2.4)$ & $0(0.0)$ \\
\hline $\begin{array}{l}\text { Reduced } \\
\text { productivity }\end{array}$ & $16(9.8)$ & $42(25.6)$ & $63(38.4)$ & $26(15.9)$ & $14(8.5)$ & $3(1.8)$ & $0(0.0)$ \\
\hline Tiredness & $13(7.9)$ & $47(28.7)$ & $58(35.4)$ & $30(18.3)$ & $13(7.9)$ & $2(1.2)$ & $1(0.6)$ \\
\hline $\begin{array}{l}\text { Poor } \\
\text { concentration }\end{array}$ & $11(6.7)$ & $46(28.0)$ & $59(36.0)$ & $34(20.7)$ & $12(7.3)$ & $1(0.6)$ & $1(0.6)$ \\
\hline Headache & $84(51.2)$ & $51(31.1)$ & $22(13.4)$ & $6(3.7)$ & $0(0.0)$ & $1(0.6)$ & $0(0.0)$ \\
\hline Worn out & $35(21.3)$ & $25(15.2)$ & $64(39.0)$ & $28(17.1)$ & $12(7.3)$ & $0(0.0)$ & $0(0.0)$ \\
\hline \multicolumn{8}{|c|}{ Practical problems } \\
\hline $\begin{array}{l}\text { Inconvenience of } \\
\text { having to carry } \\
\text { tissues or } \\
\text { handkerchief }\end{array}$ & $19(11.6)$ & $25(15.2)$ & $35(21.3)$ & $43(26.2)$ & $28(17.1)$ & $12(7.3)$ & $2(1.2)$ \\
\hline $\begin{array}{l}\text { Need to rub } \\
\text { nose/eyes }\end{array}$ & $17(10.4)$ & $39(23.8)$ & $64(39.0)$ & $24(14.6)$ & $11(6.7)$ & $8(4.9)$ & $1(0.6)$ \\
\hline $\begin{array}{l}\text { Need to blow } \\
\text { nose repeatedly }\end{array}$ & $15(9.1)$ & $34(20.7)$ & 79 (48.2) & $25(15.2)$ & $6(3.7)$ & $5(3.0)$ & $0(0.0)$ \\
\hline
\end{tabular}


Table 8: RQLQ-how troubled the patient had been by each of these symptoms during the last week.

\begin{tabular}{|llllllll|}
\hline & $\begin{array}{l}\text { Not } \\
\text { troubled }\end{array}$ & $\begin{array}{l}\text { Hardly } \\
\text { troubled at all }\end{array}$ & $\begin{array}{l}\text { Somewhat } \\
\text { troubled }\end{array}$ & $\begin{array}{l}\text { Moderately } \\
\text { troubled }\end{array}$ & $\begin{array}{l}\text { Quite a bit } \\
\text { troubled }\end{array}$ & $\begin{array}{l}\text { Very } \\
\text { troubled }\end{array}$ & $\begin{array}{l}\text { Extremely } \\
\text { troubled }\end{array}$ \\
& $\mathbf{N}(\boldsymbol{\%})$ & $\mathbf{N}(\boldsymbol{\%})$ & $\mathbf{2}$ & $\mathbf{3}$ & $\mathbf{4}$ & $\mathbf{5}$ & $\mathbf{6}$ \\
\hline Nasal symptoms & & & $\mathbf{N}(\boldsymbol{\%})$ & $\mathbf{N}(\boldsymbol{\%})$ & $\mathbf{N}(\boldsymbol{\%})$ & $\mathbf{N}(\boldsymbol{\%})$ \\
\hline Stuffy/blocked & $26(15.9)$ & $37(22.6)$ & $46(28.0)$ & $40(24.4)$ & $13(7.9)$ & $2(1.2)$ & $0(0.0)$ \\
\hline Runny & $13(7.9)$ & $21(12.8)$ & $29(17.7)$ & $54(32.9)$ & $25(15.2)$ & $18(11.0)$ & $4(2.4)$ \\
\hline Sneezing & $0(0.0)$ & $4(2.4)$ & $26(15.9)$ & $57(34.8)$ & $39(23.8)$ & $25(15.2)$ & $13(7.9)$ \\
\hline Post nasal drip & $0(0.0)$ & $63(38.4)$ & $51(31.1)$ & $41(25.0)$ & $7(4.3)$ & $1(0.6)$ & $1(0.6)$ \\
\hline Eye symptoms & & & & & & & \\
\hline Itchy eyes & $43(26.2)$ & $33(20.1)$ & $57(34.8)$ & $20(12.2)$ & $10(6.1)$ & $1(0.6)$ & $0(0.0)$ \\
\hline Watery eyes & $65(39.6)$ & $29(17.7)$ & $27(16.5)$ & $17(10.4)$ & $24(14.6)$ & $2(1.2)$ & $0(0.0)$ \\
\hline Sore eyes & $97(59.1)$ & $25(15.2)$ & $32(19.5)$ & $9(5.5)$ & $1(0.6)$ & $0(0.0)$ & $0(0.0)$ \\
\hline Swollen eyes & $106(64.6)$ & $43(26.2)$ & $15(9.1)$ & $0(0.0)$ & $0(0.0)$ & $0(0.0)$ & $0(0.0)$ \\
\hline Emotional parameters & & & & & & \\
\hline Frustrated & $39(23.8)$ & $29(17.7)$ & $55(33.5)$ & $22(13.4)$ & $14(8.5)$ & $5(3.0)$ & $0(0.0)$ \\
\hline $\begin{array}{l}\text { Impatient or } \\
\text { Restless }\end{array}$ & $31(18.9)$ & $43(26.2)$ & $47(28.7)$ & $34(20.7)$ & $6(3.7)$ & $3(1.8)$ & $0(0.0)$ \\
\hline Irritable & $12(7.3)$ & $35(21.3)$ & $63(38.4)$ & $32(19.5)$ & $19(11.6)$ & $2(1.2)$ & $1(0.6)$ \\
\hline $\begin{array}{l}\text { Embarrassed by } \\
\text { your symptoms }\end{array}$ & $56(34.1)$ & $60(36.6)$ & $27(16.5)$ & $14(8.5)$ & $6(3.7)$ & $1(0.6)$ & $0(0.0)$ \\
\hline
\end{tabular}

Then the association of all the three activities with classification of AR was assessed. It was observed that in mild intermittent AR most of the patients were 'Somewhat troubled' followed by 'moderately troubled' and none of the patient was 'extremely troubled' or could not perform activity. However, in patients of moderate to severe persistent AR most of the patients were 'quite a bit troubled' followed by 'very troubled' and 'moderately troubled'. Thus, as the severity of AR increased; the trouble of the patient in performing the activity I also increased and it was statistically significant as illustrated in Table 4 and similarly for activity II and III.

Another domain studied in the present study according to RQLQ was sleep parameters as shown in Table 5 and it is depicted in Table 6 that as the severity of AR increased; the trouble of the patient in sleep parameter i.e. 'difficulty getting to sleep' also increased and it was statistically significant.

Other domains studied in the present study according to RQLQ were non nose or eye symptoms, practical problems, nasal symptoms, eye symptoms and emotional parameters as depicted in Tables 7 and 8 and it was observed that as the severity of AR increased; the trouble of the patient in that particular parameter as per RQLQ also increased and it was statistically significant as for 'difficulty getting to sleep' as illustrated in Table 6.

\section{DISCUSSION}

$\mathrm{AR}$ is one of the most common manifestations of immunoglobulin E ( $\mathrm{IgE}$ )-mediated inflammation after allergen exposure of the nasal mucosa membrane.
In the present work the age distribution of the patients ranged from 10 years to 72 years and the mean age was 30.24 years. Maximum patients were of age group 21-30 years contributing $40.2 \%$ while among age group $>50$ years only $6.7 \%$ patients had AR. Our results were consistent with the previous studies by Cazzoletti et al, Droste et al, Olivieri et al in which the prevalence of AR peaks around the age of 16-24 years and decreases in the subsequent years up to the age of $65-70 .^{5}$ The age related decrease in the AR prevalence may be because of the decrease in allergen specific IgE level that occurs with aging in atopic individuals..$^{5-7}$

Previously AR was classified as seasonal and perennial but this classification became obsolete. Based on ARIA Guidelines 2008, AR has been classified into intermittent and persistent type and severity is classified as mild and moderate to severe type and this classification has been applied in the present study. We observed that most of the patients were having mild intermittent AR (56.1\%) and very few patients were having moderate to severe intermittent AR (3\%). Contrasting results were documented in studies by Demoly et al, Bousquet et al and Shafi et al in which most of the patients had moderate to severe intermittent and persistent AR while very few patients had mild intermittent AR. ${ }^{8-10}$

Demoly et al showed that seasonal and perennial rhinitis are not synonymous to intermittent and persistent rhinitis and they concluded that ARIA classification appears to be more appropriate than the classic form. ${ }^{11}$

In the present study dust, food, pollens, pets, others (other than the allergens mentioned in this study) were studied 
upon as triggers and it was observed that in $56.1 \%$ cases dust was the triggering factor followed by pollens $(31.1 \%)$. There is a significant association of dust and pollens with the severity of AR as depicted in our study. Various studies done in past also support our result and show a strong relationship among dust/pollutants and allergic sensitization. ${ }^{12-16}$

$\mathrm{AR}$ is an organ-specific manifestation of allergic disease and it coexists with other organ-specific disorders that have a common allergic basis. Therefore, AR is rarely found in isolation but has been frequently associated with other co-morbid disorders. ${ }^{17}$ In the present work we have studied co-morbidities associated with AR as mentioned in ARIA guidelines 2008 and we found that most common co-morbidity associated with AR was allergic conjunctivitis $(48.8 \%)$ followed by tubal dysfunction (26.8\%) while least no. of patients had adenoid hypertrophy $(4.9 \%)$. None of the patient in our study had nasal polyposis and rhinosinusitis which was in contrast to a study by Cazzoletti et al in which sinusitis was present $33.9 \%$ subjects with AR (3363 patients) and the $6.6 \%$ patients of AR reported nasal polyps. ${ }^{5}$ Similarly Passali et al reported sinusitis in $57.69 \%$ patients of AR and nasal polyposis in $36.54 \%$ patients in their study. ${ }^{17}$

In our study allergic conjunctivitis was observed mostly in patients of mild intermittent or persistent $\mathrm{AR}$ as compared to moderate to severe intermittent or persistent $\mathrm{AR}$ and it was found to be statistically significant. However, it was in contrast to a study done by Alyasin et al in which Allergic conjunctivitis was present mostly in moderate to severe intermittent or persistent $\mathrm{AR}$ patients. ${ }^{18}$

Numerous epidemiologic studies have identified allergy as a risk factor for OME. Our results show that OME is present in $16.5 \%$ of AR patients and there is a statistically significant association of OME with severity of AR. Comparable to our results Umapathy et al in their study showed that a significant association between AR and OME exist. ${ }^{19}$

AR is a chronic disease and has a negative impact on the quality of life. Bousquet et al in their study concluded that more than $80 \%$ of the patients with more severe forms of AR reported impairment in their activities due to the disease compared with only $40 \%$ of those with mild forms. ${ }^{20}$

In our study we used the RQLQ self administered Hindi version) developed by Elizabeth Jupiner, MCSP, MSc and translated by MAPI Research Institute with local coordination of Dr. Abha Saxena and printed by QOL Technologies Ltd in 2002 for determining quality of life in patients of AR.

In the present study the association of all the three Activities with classification of AR was assessed and it was found that as the severity of AR increased; the trouble of the patient in performing the activity also increased and it was statistically significant.

In our study one of the parameters assessed for quality of life as per RQLQ was sleep. Our results were confirmed by the observations made by La-Grutta et al in their study on Spanish adolescents (aged 12-18 years) with respiratory allergies including AR who suggested that the adolescents experienced difficulties falling asleep, night waking, and poor sleep as a consequence of their condition. ${ }^{21}$ Our results are comparable to the survey done by Blaiss et al in patients of AR which depicted that $68 \%$ patients with perennial AR and $48 \%$ patients with seasonal AR reported that the disease interfered with their sleep and affected their quality of life. ${ }^{22}$ Similar results were observed in a French cohort where the prevalence of sleep disorders (insomnia) was around $14 \%$ in mild AR and $40-42 \%$ in moderate-severe AR. ${ }^{23}$

Another domain studied in the present study according to RQLQ was non nose or eye symptoms which were fatigue, thirst, reduced productivity, tiredness, poor concentration, headache and worn out and the results were similar to the sleep parameters as mentioned before. Our results were consistent with the observations made by Leger et al who reported that $43.7 \%$ of patients with AR suffer from fatigue even when they sleep normally at night. Their headaches, anxiety, depression, and daytime sleepiness are significantly higher compared to those without AR. ${ }^{23}$

Certain practical problems mentioned in RQLQ have been studied in the present study and the results were comparable to a study performed by Dziekanski et al which utilised modified RQLQ (RQLQm) for determining quality of life; among "practical problems," to wipe the nose repeatedly was the one that most caused discomfort, followed by to rub the nose repeatedly, having to carry handkerchiefs and having to take medication in smaller proportions. ${ }^{24}$

Another domain mentioned in the RQLQ and taken into consideration in the present study is of Nasal Symptoms which are really very annoying to the patient and affects quality of life in patients of AR. The results were similar to the other domains mentioned before and it was observed that as the severity of AR increased; the trouble of the patient in nasal symptoms also increased.

In a study by Dziekanski et al who utilised RQLQm; regarding the "nasal symptom score," nasal itchiness predominated. None of the interviewed cited nasal itchiness as absent. Runny nose appeared to be uncomfortable a few times and the symptoms headache and itchy eyes generally bothered less the respondents. ${ }^{24}$

Another domain studied was of eye symptoms which showed that in parameter 'itchy eyes' the patient was mostly 'somewhat troubled'. in parameters 'watery eyes', 'sore eyes' and 'swollen eyes' most of the patients were 
'not troubled'. The results were similar to the other domains as mentioned before and were comparable to the results depicted in a study by Belgu et al who found that in the group with coexistent allergic conjunctivitis, RQLQ scores of sleep, non-hay fever complaints, nasal complaints, ophthalmic complaints, and restricted activities were significantly higher compared to the group without $\mathrm{AC}(\mathrm{p}<0.05){ }^{25}$

In the present study the emotional problems (as per RQLQ) that were studied included 'frustrated, 'impatient or restless', 'irritable' and 'embarrassed by your symptoms'. The results were similar to the other domains as mentioned before and it was observed that as the severity of AR increased; the duration for trouble for the patient in emotional problems (as per RQLQ) also increased and it was statistically significant.

In a study by Dziekanski et al in the emotions domain, a small proportion of patients reported being bothered in the previous week by feeling impatient and irritable, followed by anxious, nervous, embarrassed and angry. ${ }^{24}$ A large online survey performed by Meltzer et al reported that a considerable proportion of the parents of US adolescents (aged 12-17 years) with AR thought their child's condition made them unhappy, upset, angry, and embarrassed. ${ }^{26}$

Results found in other studies were satisfactory in estimating the impact of AR on the QoL of the interviewed through RQLQm. Among these studies the average subjective severity score of the disease and quality of life scores were high, indicating that the QoL was considered moderate to low thus confirming the results obtained from this study. ${ }^{27-29}$

Thus, on the basis of present study we conclude that ARIA guidelines are appropriate and should be applied to classify patients of AR and should be implicated to determine the associated comorbidities and clinicians should keep in mind the associated comoribidities as mentioned in ARIA guidelines so that appropriated management can be accomplished. The quality of life questionnaire should also be applied to determine the effect on the quality of life as well depicted in the results of the present study.

\section{ACKNOWLEDGEMENTS}

I would like to express my wholehearted respect and gratitude towards Dr. Rohit Sharma and Dr. Vinit Sharma whose constant help, guidance, moral support and encouragement prompted me to do this work.

Funding: No funding sources Conflict of interest: None declared

Ethical approval: The study was approved by the Institutional Ethics Committee

\section{REFERENCES}

1. Bousquet $\mathrm{J}$, van Cauwenberge $\mathrm{P}$, Khaltaev $\mathrm{N}$. Allergic Rhinitis and Its Impact on Asthma. J Allergy Clin Immunol. 2001;108(5):147-334.

2. Bousquet J, Khaltaev N, Cruz AA, Denburg J, Fokkens WJ, Togias A et al. Allergic Rhinitis and its Impact on Asthma (ARIA) 2008 update (in collaboration with the World Health Organization, GA(2)LEN and Aller Gen). Allergy. 2008;63:8-160.

3. Pereira C, Valero A, Loureiro C, Davila I, MartinezCocera C, Murio C, et al. Iberian study of aeroallergens sensitization in allergic rhinitis. European Annals Allergy Clin Immunol. 2006;38:186-94.

4. Navarro A, Valero A, Julia B, Quirce S. Coexistence of Asthma and Allergic Rhinitis in Adult Patients Attending Allergy Clinics: ONEAIR Study. J Investigational Allergol Clin Immunol. 2008;18(4):233-8.

5. Cazzoletti L, Ferrari M, Olivieri M, Verlato G, Antonicelli L, Bono R, et al. The gender, age and risk factor distribution differs in self-reported allergic and non-allergic rhinitis: a cross-sectional population-based study. Allergy Asthma Clin Immunol. 2015;11:36.

6. Droste JHJ, Kerkhof M, De Monchy JGR, Schouten JP, Rijcken B. Association of skin test reactivity, specific IgE, total IgE, and eosinophils with nasal symptoms in a community-based population study. $\mathbf{J}$ Allergy Clin Immunol. 1996;97:922-32.

7. Olivieri M, Verlato G, Corsico A, Lo Cascio V, Bugiani M, Marinoni A et al. Prevalence and features of allergic rhinitis in Italy. Allergy. 2002;57:600-6.

8. Demoly P, Aubier M, Blay F, Wessel F, Clerson P, Maigret P. Evaluation of patients' expectations and benefits in the treatment of allergic rhinitis with a new tool: the patient benefit index. Allergy, Asthma Clin Immunol. 2015;11:8.

9. Bousquet L, Annesi-Maesano I, Carat F. Characteristics of intermittent and persistent allergic rhinitis: DREAMS study group. Clin Exp Allergy. 2005;35(6):728-32.

10. Shafi M, Ghouri A, Aslam S, Hanif R. Frequency of Allergic Rhinitis in Patients with Bronchial Asthma at a Tertiary Care Hospital. Isra Med J. 2018;10(1):3-7.

11. Demoly P, Allaert FA, Lecasble M, Bousquet J. Validation of the classification of ARIA (allergic rhinitis and its impact on asthma). Allergy. 2003;58(7):672-5.

12. Bousquet J, Fokkens W, Burney P, Durham SR, Bachert C, Akdis CA et al. Important research questions in allergy and related diseases: nonallergic rhinitis: a GA2LEN paper. Allergy. 2008;63:842-53.

13. Mösges R, Klimek L. Today's allergic rhinitis patients are different: new factors that may play a role. Allergy. 2007;62:969-75. 
14. Gehring U, Wijga AH, Brauer M, Fischer P, de Jongste JC, Kerkhof $M$ et al. Traffic-related air pollution and the development of asthma and allergies during the first 8 years of life. Am J Respir Crit Care Med. 2010;181:596-603.

15. Wyler C, Braun-Fahrländer C, Künzli N, Schindler C, Ackermann-Liebrich U, Perruchoud AP et al. Exposure to motor vehicle traffic and allergic sensitization. Epidemiology. 2000;11:450-6.

16. Cesaroni G, Badaloni C, Porta D, Forastiere F, Perucci CA. Comparison between various indices of exposure to traffic-related air pollution and their impact on respiratory health in adults. Occup Environ Med. 2008;65:683-90.

17. Passali D, Cingi C, Staffa P, Passali F, Muluk NB, Bellussi ML. The International Study of the Allergic Rhinitis Survey: outcomes from four geographical regions. Asia Pac Allergy. 2018;8(1):7.

18. Alyasin S, Amin R. The Evaluation of New Classification of Allergic Rhinitis in Patients Referred to a Clinic in the City of Shiraz. Iranian J Allergy Asthma Immunol. 2007;6(1):27-31.

19. Umapathy D, Alles R, Scadding GK. A community based questionnaire study on the association between symptoms suggestive of otitis media with effusion, rhinitis and asthma in primary school children. Int J Pediatr Otorhinolaryngol. 2007;71(11):705-12.

20. Bousquet J, Neukirch F, Bousquet P, Gehano P, Klossek J, Legal M et al. Severity and impairment of allergic rhinitis in patients consulting in primary care. J Allergy Clin Immunol. 2006;117(1):158-62.

21. La Grutta S, Landi M, Braido F, Montalbano L, Ferrante G, Malizia V. RHINASTHMAAdolescents: a new quality of life tool for patients with respiratory allergy. Pediatr Allergy Immunol. 2014;25:450-5.

22. Blaiss M, Reigel T, Philpot E. A study to determine the impact of rhinitis on sufferers sleep and daily routine. J Allergy Clin Immunol. 2005;115:197.

23. Leger D, Annesi-Maesano I, Carat F, Rugina M, Chanal I, Pribil C, et al. Allergic rhinitis and its consequences on quality of sleep: An unexplored area. Arch Intern Med. 2006;166(16):1744-8.

24. Dziekanski M, Marcelino TF. Quality of Life in Pediatric Patients with Allergic Rhinitis treated at the Medical Clinic of Integrated Education - Unisul. Int Arch Otorhinolaryngol. 2017;21:371-6.

25. Bisaccioni C, Aun MV, Cajuela E, Kalil J, Agondi RC, Giavina-Bianchi P. Comorbidities in severe asthma: frequency of rhinitis, nasal polyposis, gastroesophageal reflux disease, vocal cord dysfunction and bronchiectasis. Clinics. 2009;64(8):769-73.

26. Meltzer EO, Farrar JR, Sennett C. Findings from an online survey assessing the burden and management of seasonal allergic rhinoconjunctivitis in US patients. J Allergy Clin Immunol Pract. 2017;5:779-89.

27. Valero A, Mullol J, Herdman M, Rosales MJ. Measuring outcomes in allergic rhinitis: psychometric characteristics of a Spanish version of the congestion quantifier seven-item test (CQ7). Health Qual Life Outcomes. 2011;9(01):14.

28. Nascimento Silva M, Naspitz C, Solé D. Evaluation of quality of life in children and teenagers with allergic rhinitis: adaptation and validation of the Rhinoconjunctivitis Quality of Life Questionnaire (RQLQ). Allergol Immunopathol. 2001;29(04):111-8.

29. Bousquet PJ, Demoly P, Devillier P,Mesbah K, Bousquet J. Impact of allergic rhinitis symptoms on quality of life in primary care. Int Arch Allergy Immunol. 2013;160(04):393-400.

Cite this article as: Agarwal AK, Sharma R, Sharma V. Application of allergic rhinitis and its impact on asthma guidelines in terms of classification, risk factors, quality of life and co-morbidities in allergic rhinitis patients in Northern India. Int $\mathbf{J}$ Otorhinolaryngol Head Neck Surg 2020;6:1082-90. 